\title{
The Brockenbrough-Braunwald-Morrow sign
}

Hao Cui, MD, PhD, Anita Nguyen, MBBS, and Hartzell V. Schaff, MD

From the Department of Cardiovascular Surgery, Mayo Clinic, Rochester, Minn.

This work was supported by the Paul and Ruby Tsai Family.

Disclosures: Authors have nothing to disclose with regard to commercial support.

Received for publication March 9, 2018; accepted for publication April 24, 2018; available ahead of print June 5, 2018.

Address for reprints: Hartzell V. Schaff, MD, Department of Cardiovascular Surgery, Mayo Clinic, 200 First St SW, Rochester, MN 55905 (E-mail: schaff@mayo.edu).

J Thorac Cardiovasc Surg 2018;156:1614-5

$0022-5223 / \$ 36.00$

Copyright $(2018$ by The American Association for Thoracic Surgery

https://doi.org/10.1016/j.jtcvs.2018.04.095

The Brockenbrough-Braunwald-Morrow sign was first described in patients with obstructive hypertrophic cardiomyopathy (HCM) by Brockenbrough and colleagues ${ }^{1}$ in
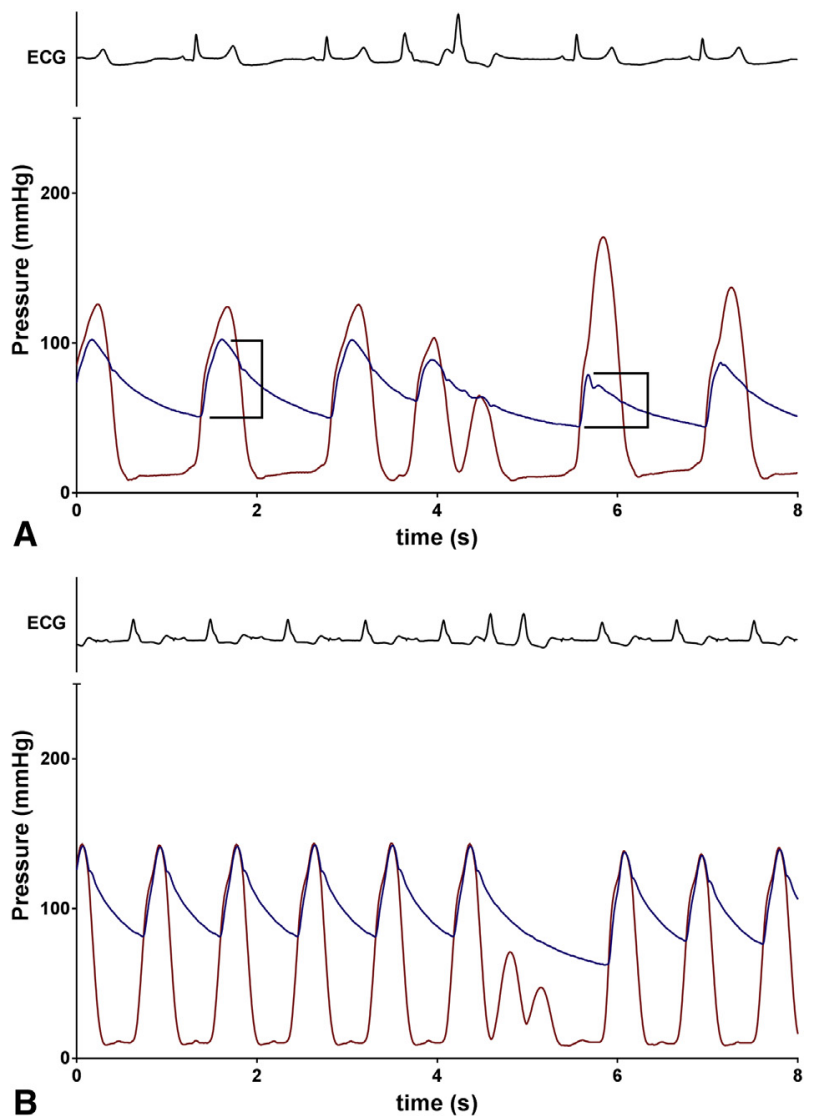

FIGURE 1. Brockenbrough-Braunwald-Morrow sign in obstructive hypertrophic cardiomyopathy. A, Left ventricular pressure tracing superimposed on aortic pressure tracing shows a typical BrockenbroughBraunwald-Morrow sign before septal myectomy, with significant decrease in pulse pressure after a premature ventricular contraction. B, In the postbypass tracing, after septal myectomy, it can be seen that the premature ventricular contraction did not trigger the Brockenbrough-BraunwaldMorrow sign. Red line indicates left ventricular pressure tracing; blue line indicates aortic pressure tracing; brackets indicate pulse pressure before and after premature ventricular contraction. ECG, Electrocardiogram.

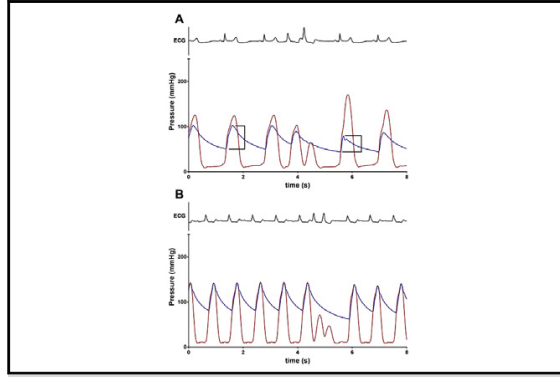

The Brockenbrough-Braunwald-Morrow sign in a patient with obstructive HCM.

\section{Central Message}

The Brockenbrough-Braunwald-Morrow sign is characteristic of dynamic LV outflow tract obstruction, as is seen in obstructive HCM, but is uncommon in fixed valvular or subvalvular obstruction.

See Editorial Commentary page 1616.

the 1960s. This sign is characterized by a decrease in arterial pulse pressure after a premature ventricular contraction (PVC), accompanied by a significant increase in peak left ventricular (LV) systolic pressure. In patients without dynamic outflow obstruction, the longer filling period after a PVC increases LV end-diastolic volume; this and postextrasystolic potentiation increase both stroke volume and arterial pulse pressure. ${ }^{1,2}$ In patients with obstructive HCM, provocation with a PVC leads to a paradoxic decrease in pulse pressure. Maneuvers to elicit the BrockenbroughBraunwald-Morrow sign are frequently used to establish the diagnosis of obstructive HCM during cardiac catheterization and to assess the adequacy of septal reduction after surgical myectomy or alcohol septal ablation.,

Figure 1 illustrates the Brockenbrough-BraunwaldMorrow sign in a 65-year-old man with obstructive HCM before and after transaortic septal myectomy. For comparison, we present intraoperative pressure tracings from $2 \mathrm{pa}-$ tients with fixed LV outflow tract obstruction. The patient in Figure 2 is a 69 -year-old man with aortic valvular stenosis, and Figure 3 shows pressure tracings from a 64-year-old woman with membranous and tunnel subaortic stenosis not associated with systolic anterior motion of the mitral valve.

At operation, LV and aortic pressures were simultaneously traced with high-fidelity catheters before and after cardiopulmonary bypass. We observed the BrockenbroughBraunwald-Morrow sign in the patient with obstructive 

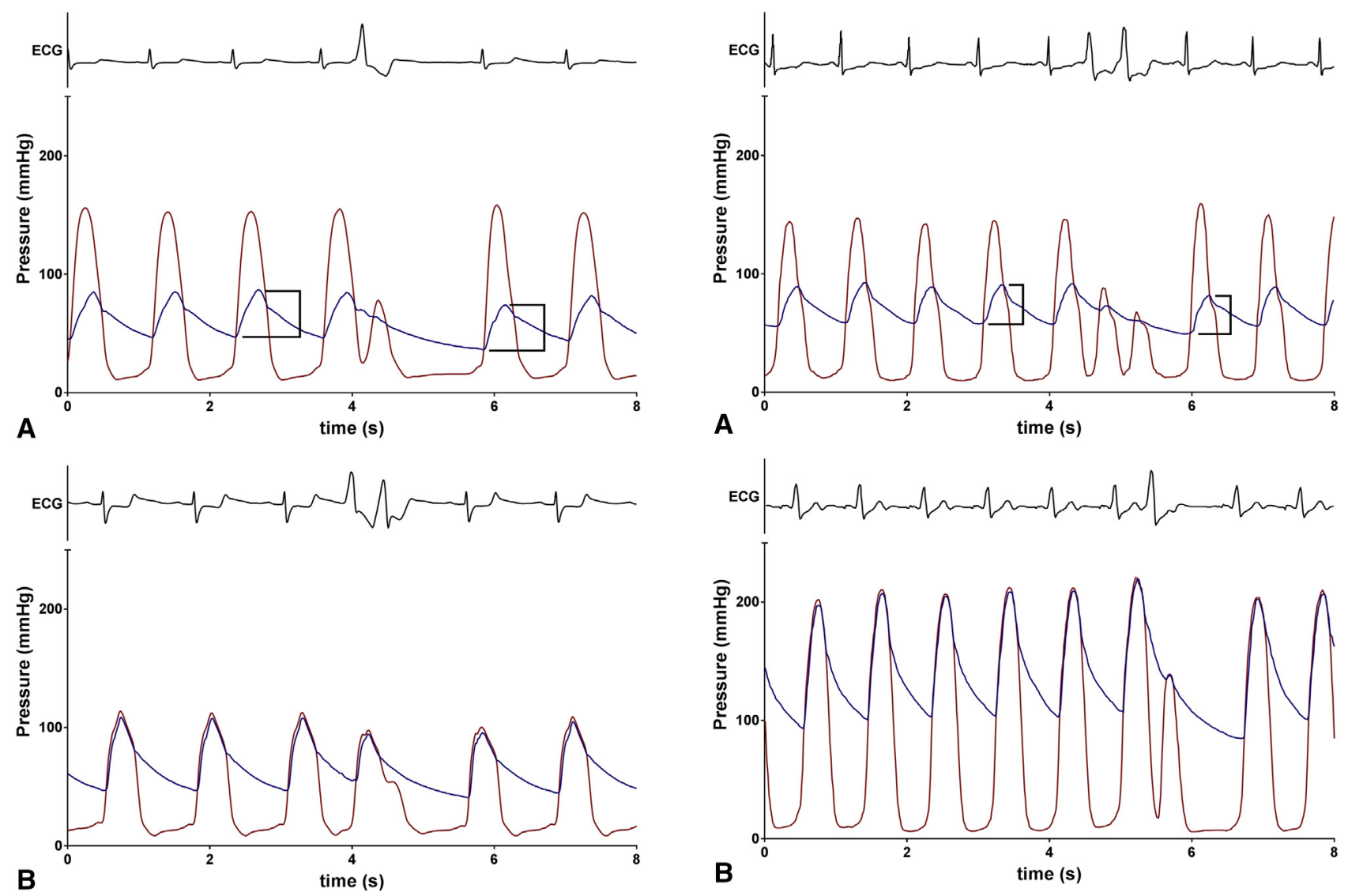

FIGURE 2. Left ventricular pressure tracing superimposed on aortic pressure tracing in a patient with valvular aortic stenosis. A, In this patient, pulse pressure did not change after a premature ventricular contraction. B, No post-premature ventricular contraction changes in pulse pressure are seen after aortic valve replacement. Red line indicates left ventricular pressure tracing; blue line indicates aortic pressure tracing; brackets indicate pulse pressure before and after premature ventricular contraction. $E C G$, Electrocardiogram.

HCM (Figure 1, A), with a significant decrease in arterial pulse pressure after a PVC. The sign disappeared after septal myectomy, and pulse pressure remained stable after provocation (Figure $1, B$ ). In the 2 patients with aortic stenosis and subvalvular stenosis (Figures 2 and 3), prebypass arterial pulse pressure did not change after PVC. As expected, the Brockenbrough-Braunwald-Morrow sign could not be elicited in these patients.

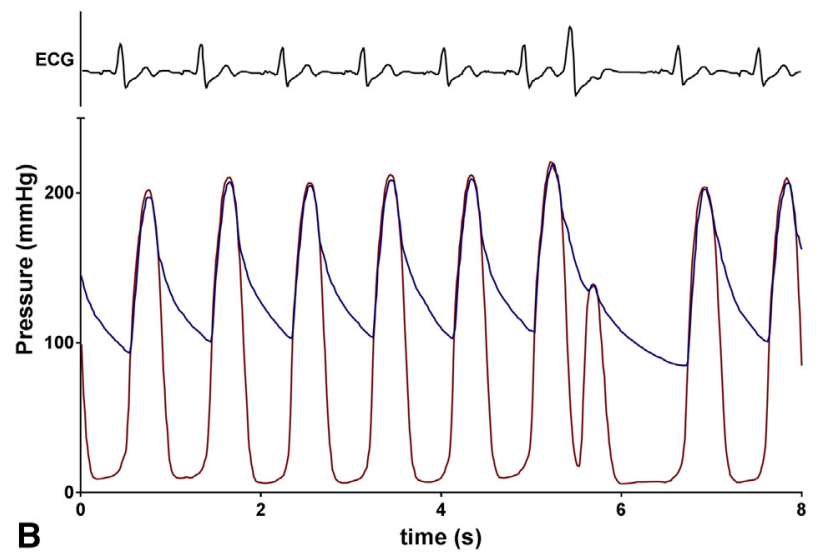

FIGURE 3. Left ventricular pressure tracing superimposed on aortic pressure tracing in a patient with membranous and tunnel subaortic stenosis. A, No post-premature ventricular contraction change in pulse pressure was seen before the operation. B, After membranectomy and myectomy, there was a slight widening of arterial pulse pressure after premature ventricular contraction. Red line indicates left ventricular pressure tracing; blue line indicates aortic pressure tracing; brackets indicate pulse pressure before and after premature ventricular contraction. ECG, Electrocardiogram.

\section{References}

1. Brockenbrough EC, Braunwald E, Morrow AG. A hemodynamic technic for the detection of hypertrophic subaortic stenosis. Circulation. 1961;23:189-94.

2. Cooper MW. Postextrasystolic potentiation. Do we really know what it means and how to use it? Circulation. 1993;88:2962-71.

3. Ashikhmina EA, Schaff HV, Ommen SR, Dearani JA, Nishimura RA, Abel MD. Intraoperative direct measurement of left ventricular outflow tract gradients to guide surgical myectomy for hypertrophic cardiomyopathy. J Thorac Cardiovasc Surg. 2011;142:53-9.

4. Nishimura RA, Seggewiss H, Schaff HV. Hypertrophic obstructive cardiomyopathy: surgical myectomy and septal ablation. Circ Res. 2017;121:771-83. 